\title{
PENGARUH KOMPOSISI WARNA \& OBJEK PENDUKUNG PADA WINDOW DISPLAY TERHADAP CUSTOMER PERCEIVED VALUE DARI PRODUK BATIK KERATON YOGYAKARTA
}

\author{
Annisya Syahreni Syahrial, Imam Santosa, dan Prabu Wardono \\ Program Studi Magister Desain Institut Teknologi Bandung
}

\begin{abstract}
ABSTRAK
Window display mampu menjadi media atau perantara untuk meningkatkan customer perceived value (CPV) dari suatu produk, dalam penelitian ini produk yang digunakan adalah produk batik keraton Yogyakarta. Untuk mendukung citra visual dari batik keraton Yogyakarta, warna yang digunakan pada penelitian ini adalah warna yang dapat menunjukkan suasana Jawa dan skema warna monochrome digunakan sebagai pembanding. Objek pendukung (props) digunakan sebagai pendukung dari penciptaan efek penggunaan warna pada window display. Objek pendukung yang digunakan pada penelitian ini adalah objek pendukung berbentuk 2D dan 3D. Penelitian ini menggunakan metode kuantitatif dengan pengambilan data melalui pengamatan dan penilaian simulasi digital window display dalam bentuk tiga dimensional (3D) melalui kuesioner secara online. Simulasi window display diberikan treatment warna (skema warna Yogyakarta dan monochrome) dan objek pendukung (props) (2D dan 3D). Melalui uji-t untuk sampel bebas dan uji twoway ANOVA diketahui bahwa skema warna Jawa / Yogyakarta dan objek pendukung (props) terutama dalam bentuk 3D memiliki peran positif terhadap pembentukan CPV dari produk batik keraton Yogyakarta di toko fashion. Hasil tersebut mendukung temuan Hanna Kiehelä (2014), yaitu elemen warna pada retail design berpengaruh pada pembentukan perceived value pada produk yang dijual dan mendukung teori Nassar (1988), yaitu objek pendukung berupa tekstur atau tiga dimensional merupakan salah satu sumber daya visual penting karena dapat meningkatkan kualitas lingkungan dan memberikan efek visual yang menyenangkan
\end{abstract}

Kata Kunci: Customer Perceived Value, Objek Pendukung, Warna, Window Display

\section{PENDAHULUAN}

Merancang desain sebuah toko untuk menghasilkan store atmosphere yang tepat tidaklah mudah. Untuk itu para pemilik toko perlu mencari cara efektif untuk memberikan informasi mengenai produk atau jasanya agar minat beli pengunjung meningkat. Salah satu caranya adalah dengan menciptakan persepsi visual yang baik oleh pengunjung terhadap sebuah toko. Tordiglione (2015) mengatakan bahwa shopfront atau tampak depan toko merupakan metode utama untuk mengiklankan produk dan meningkatkan bisnis. Shopfront terdiri dari beberapa bagian yang secara keseluruhan membentuk komposisi visual. Menurut Tordiglione (2015), bagian utama dari shopfront adalah fascia (papan nama toko), cornice (batas dengan lantai atas yang juga merupakan bingkai dari fascia), windows (jendela untuk menampilkan produk atau memperlihatkan isi toko), entrance (pintu masuk toko), pilasters (batas dengan toko atau bangunan samping yang juga merupakan bingkai dari windows), dan stall riser (batas bawah toko dengan lantai, berfungsi juga sebagai window's base)

Salah satu bagian shopfront yang memperlihatkan produk yang dijual adalah windows atau biasa disebut window display. Window display adalah bagian terdepan dari sebuah toko yang merupakan bidang tembus pandang dan berfungsi untuk menarik perhatian orang-orang yang melewatinya (Mun, 1981). Menurut Berman dan Evans, 
window display memiliki dua fungsi utama, yaitu untuk mengidentifikasi sebuah toko beserta produk atau jasa yang ditawarkannya, dan juga untuk membujuk konsumen agar berbelanja di toko tersebut (Yildrim, Baskaya, Hidayetoglu, 2007). Beragam elemen desain digunakan pada window display di fashion retail untuk menarik perhatian pengunjung. Morgan (2008) mengelompokkan elemen-elemen desain window display menjadi lima kelompok, yaitu komposisi layout, komposisi bentuk, komposisi warna, komposisi cahaya, dan komposisi grafis (ilustrasi dan teks). Elemen-elemen desain window display tersebut dapat mendukung tema dan skema yang digunakan pada sebuah window display. Ditinjau dari fungsi utamanya, window display sebuah toko berfungsi untuk menarik perhatian pengunjung sebagai pembentuk persepsi visual guna meningkatkan minat beli, terutama pada fashion retail. Oleh karena itu, window display dapat mempengaruhi customer perceived value pengunjung terhadap produk yang dipajang. Customer perceived value (CPV) adalah penilaian konsumen yang dilakukan dengan cara membandingkan antara manfaat atau kegunaan suatu produk atas apa yang diterima dan apa yang diberikan oleh suatu produk atau jasa. Melalui fashion retail, produk batik dapat terus berkembang dan dikenal oleh masyarakat. Customer perceived value dari corak batik keraton Yogyakarta dalam sebuah fashion retail dapat ditingkatkan melalui window display. Dari kelima elemen desain, yaitu komposisi layout, komposisi bentuk, komposisi warna, komposisi cahaya, dan komposisi grafis (ilustrasi dan teks), warna dan cahaya merupakan aspek yang paling penting dalam perancangan window display karena merupakan aspek yang paling berpengaruh terhadap minat beli konsumen dan peningkatan nilai produk (Somoon \& Chumporn, 2016; Hanna Kiehelä, 2014). Penggunaan warna dan cahaya yang berbeda dapat memberikan pengaruh yang berbeda-beda pada setiap pengunjung dalam menilai produk yang dipajang. Untuk mendukung citra visual dari batik keraton Yogyakarta, warnawarna yang digunakan pada penelitian ini adalah warna-warna yang dapat menunjukkan suasana Jawa untuk mendukung pembentukan persepsi oleh pengunjung. Sedangkan skema warna yang digunakan sebagai pembanding pada penelitian ini adalah skema warna monochrome karena menurut sumber literatur skema warna monochrome merupakan skema warna yang efektif untuk digunakan pada window display. Objek pendukung atau props digunakan pada penelitian ini sebagai pendukung dari penciptaan efek penggunaan warna pada window display. Objek pendukung (props) yang digunakan pada penelitian ini terbagi menjadi objek pendukung berbentuk 2D (grafis) dan objek pendukung berbentuk 3D (furniture). Untuk melihat pengaruh dari penggunaan skema warna dan objek pendukung yang berbeda, dilakukan penelitian lanjutan melalui eksperimen.

Tujuan dari penelitian ini adalah: (1) Mengembangkan pengetahuan mengenai adanya hubungan antara tampilan window display di toko fashion terhadap customer perceived value dari produk batik keraton Yogyakarta; (2) Mengetahui seberapa besar peran komposisi warna dan objek pendukung (props) pada window display di toko fashion terhadap customer perceived value dari produk batik keraton Yogyakarta; dan (3) Membuktikan bahwa penggunaan elemen desain tradisional Jawa pada window display di toko fashion memiliki pengaruh terhadap customer perceived value dari produk batik keraton Yogyakarta.

\section{METODE PENELITIAN}

Desain penelitian ini menggunakan metode penelitian kuantitatif. Menurut Cooper \& Schindler (2004), penelitian kuantitatif mencoba melakukan pengukuran yang akurat terhadap sesuatu. Dalam penelitian ini akan dilakukan akuisisi data numerik yang 
diperlukan yang kemudian melakukan perhitungan statistik pengukuran yang diperlukan untuk menentukan hubungan antara variabel independen sistem pencahayaan berwarna dan variabel terikat persepsi naracoba. Adapun wawancara dan dokumentasi dalam pendekatan ini hasilnya dikuantifikasikan ke dalam angka-angka yang sudah ditentukan sesuai dengan ketentuan yang ada. Adapun spesifikasi penelitian ini adalah bersifat deskriptif yaitu untuk mengangkat fakta, keadaan, variabel, dan fenomena-fenomena yang terjadi sekarang (ketika penelitian berlangsung) dan penyajiannya apa adanya. Penelitian ini merupakan penelitian yang mengarah pada studi korelasional. Studi korelasi ini merupakan hubungan antar dua variabel, tidak saja dalam bentuk sebab akibat melainkan juga timbal balik antara dua variabel (Sugiyono, 2006). Dengan metode ini, penulis akan mendeskripsikan tentang korelasi komposisi warna dan objek pendukung (props) pada window display dengan customer perceived value dari produk batik keraton Yogyakarta. Desain penelitian ini menggunakan sequential explanatory. Proses penelitian kuantitatif secara umum harus memenuhi tahapan perumusan masalah, telaah teoretis, verifikasi data, dan kesimpulan. Penelitian kuantitatif memerlukan adanya hipotesis dan pengujiannya yang kemudian akan menentukan tahapan-tahapan berikutnya, seperti penentuan teknik analisa dan formula statistik yang akan digunakan. Penelitian kuantitatif pada penelitian ini dilaksanakan dengan melakukan eksperimentatif simulatif melalui simulasi digital desain window display dengan produk batik keraton Yogyakarta. Metode eksperimentatif simulatif menggunakan simulasi digital dalam eksperimen sehingga hasil dari penelitian ini bukan merupakan hasil yang akurat $(100 \%)$. Hal tersebut dikarenakan terdapat aspek-aspek pada kondisi nyata yang tidak dapat dimunculkan pada saat pelaksanaan eksperimen melalui simulasi digital.

\section{HIPOTESIS PENELITIAN}

Berdasarkan stimulus dan variabel penelitian, maka dalam penelitian ini disusun hipotesis sebagai berikut:

1. Tampilan window display berpengaruh terhadap customer perceived value dari produk batik keraton Yogyakarta.

2. Penggunaan desain tradisional Jawa pada window display dapat meningkatkan customer perceived value dari produk batik keraton Yogyakarta.

3. Komposisi warna Yogyakarta pada window display dapat meningkatkan customer perceived value dari produk batik keraton Yogyakarta.

4. Objek pendukung (props) dalam bentuk tiga dimensi (3D) pada window display dapat meningkatkan customer perceived value dari produk batik keraton Yogyakarta.

\section{SUBJEK \& OBJEK PENELITIAN (STIMULUS)}

Subjek penelitian ini adalah masyarakat dengan kondisi ekonomi menengah ke atas yang pernah mengunjungi pusat perbelanjaan atau mall dan pernah menggunakan produk batik. Subjek penelitian berada dalam rentang usia antara 20 tahun hingga 65 tahun. Objek yang diteliti atau stimulus yang digunakan pada penelitian ini dibagi menjadi tiga unsur, yaitu window display, warna, dan objek pendukung (props). Stimulus pertama berupa simulasi digital sebuah window display. Window display tersebut dirancang dengan tema dan skema interior bergaya Jawa dan interior bergaya modern. Komposisi layout yang digunakan pada penelitian ini dibatasi pada komposisi layout simetris dan komposisi layout asimetris. Komposisi cahaya yang digunakan pada penelitian ini dibatasi pada pencahayaan hangat, yaitu warna cahaya yang menimbulkan kesan hangat (warm) dengan suhu $2500 \mathrm{~K}$ (accent lighting) dan 3000K (general lighting). Simulasi digital window 
display menggunakan tema dan skema interior bergaya Jawa dan bergaya modern dengan produk fashion batik keraton Yogyakarta.

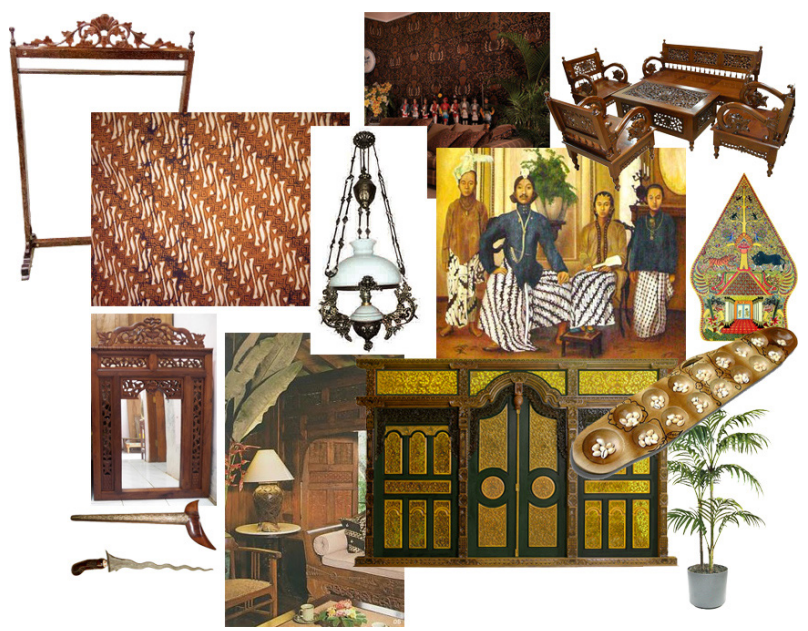

Gambar 1. Mood Board Simulasi Digital Window Display Bergaya Jawa

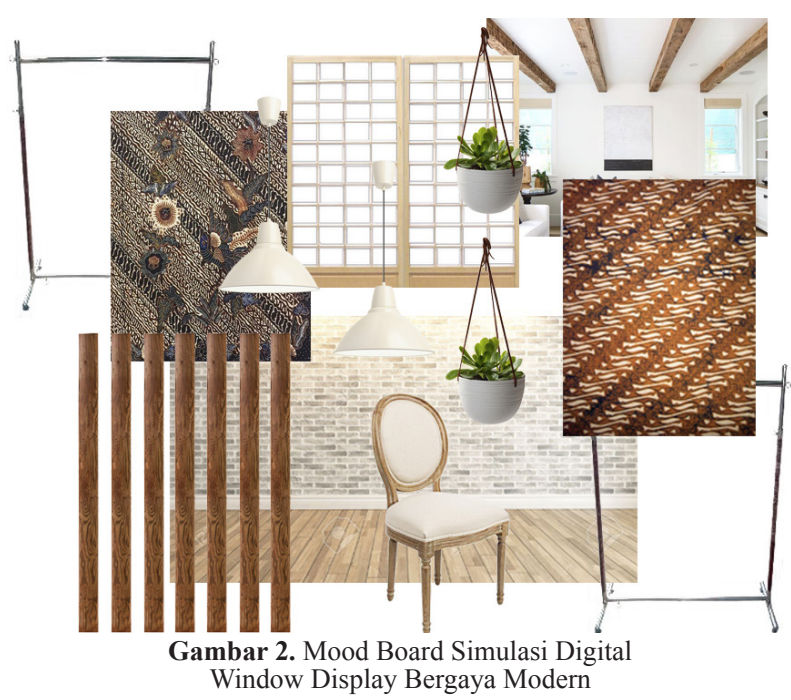

Stimulus kedua berupa komposisi warna yang digunakan pada simulasi window display, yaitu dibatasi pada komposisi warna Yogyakarta dan warna monochrome yang diterapkan pada simulasi digital window display.

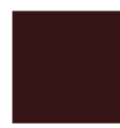

R 54

G 20

B 21

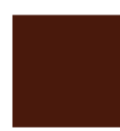

73

25

12

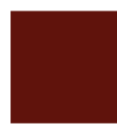

97

18

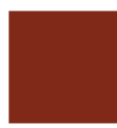

129

41 25

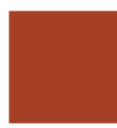

165

63 35

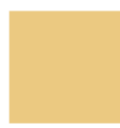

235

201 129

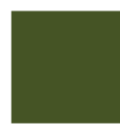

$69 \quad 254$

$84 \quad 215$

$37 \quad 0$

Gambar 3. Skema Warna Yogyakarta yang Digunakan pada Simulasi Digital Window Display 


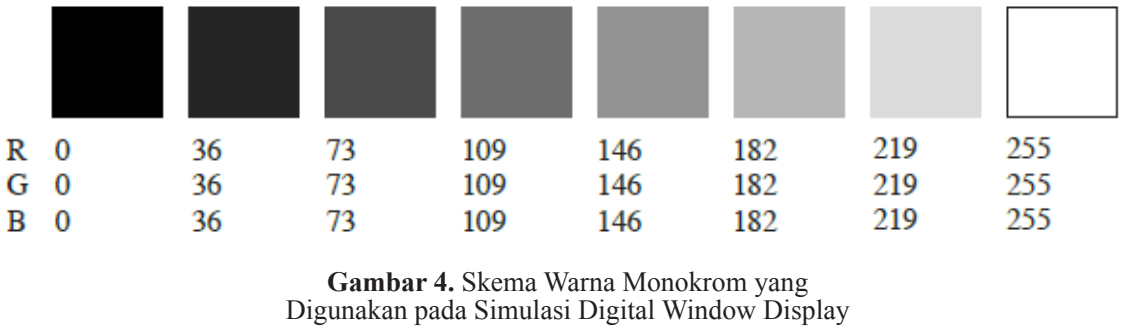

Stimulus ketiga berupa objek pendukung (props) yang digunakan pada simulasi window display, yaitu objek pendukung (props) berbentuk dua dimensi (2D) yang mampu mendukung penciptaan suasana interior tradisional Jawa, seperti kain batik yang diberi pigura, wallpaper batik, backdrop gambar suasana jawa, dan lain-lain; dan Objek pendukung (props) berbentuk tiga dimensi (3D) yang mampu mendukung penciptaan suasana interior tradisional Jawa, seperti lampu katrol Jawa, gebyok, gawangan, cermin Jawa, keris, congklak, dan lain-lain.

\section{VARIABEL}

Variabel kontrol pada penelitian ini berupa simulasi window display menggunakan tema dan skema interior bergaya Jawa dan bergaya modern dengan produk fashion batik keraton Yogyakarta. Variabel independent pada penelitian ini adalah warna (komposisi warna Yogyakarta dan monochrome) dan objek pendukung (props) yang digunakan pada ilustrasi window display (2D dan 3D). Variabel dependent pada penelitian ini adalah customer perceived value dan daya tarik terhadap produk batik keraton Yogyakarta menurut subjek penelitian setelah melihat ilustrasi window display.

Tabel 1. Kombinasi Variabel Independent

\begin{tabular}{c|l|l|}
\multicolumn{2}{c}{ 2D } \\
\multicolumn{1}{c}{\begin{tabular}{c}
\multicolumn{2}{c}{ Objek Pendukung (Props) } \\
(Yogyakarta)
\end{tabular}} & $\begin{array}{l}\text { Skema warna Yogyakarta } \\
\text { dengan objek pendukung } \\
\text { (props) berbentuk dua } \\
\text { dimensi (2D) }\end{array}$ & $\begin{array}{l}\text { Skema warna Yogyakarta } \\
\text { dengan objek pendukung } \\
\text { (props) berbentuk tiga } \\
\text { dimensi (3D) }\end{array}$ \\
\cline { 3 - 4 } $\begin{array}{l}\text { Skema } \\
\text { Warna }\end{array}$ & $\begin{array}{l}\text { Skema warna } \\
\text { monochrome } \\
\text { dengan objek pendukung } \\
\text { (props) berbentuk dua } \\
\text { dimensi (2D) }\end{array}$ & $\begin{array}{l}\text { Skema warna monochrome } \\
\text { dengan objek pendukung } \\
\text { (props) berbentuk tiga } \\
\text { dimensi (3D) }\end{array}$ \\
\hline
\end{tabular}

\section{PROSEDUR PELAKSANAAN PENELITIAN}

Penelitian ini terdiri dari beberapa tahap, dimulai dengan pencarian data hingga eksperimen. Pada tahap eksperimen, subjek penelitian akan mengamati simulasi digital desain window display secara tiga dimensional (3D) melalui kuesioner secara online. Simulasi digital ini diberikan secara 3D untuk memperlihatkan efek penggunaan warna, efek cahaya, dan efek objek pendukung (props) pada window display sehingga dapat menimbulkan bayangan dan kesan ruang. Tahap eksperimen dilakukan dengan tujuan untuk mengetahui nilai kualitas, nilai emosi, nilai harga, dan nilai sosial produk yang diciptakan oleh ilustrasi tiga dimensional (3D) window display, serta mengetahui hubungan antara 
window display dan customer perceived value dari produk batik keraton Yogyakarta berdasarkan ilustrasi tiga dimensional (3D) window display. Pada saat eksperimen, subjek penelitian akan mengamati salah satu dari 5 (lima) simulasi digital window display yang muncul secara acak (random) yang telah dimanipulasi sesuai dengan variabel kontrol dan variabel independent, yaitu (1) Window display dengan interior bergaya modern; (2) Window display dengan interior bergaya tradisional Jawa menggunakan komposisi warna Yogyakarta dan objek pendukung (props) berbentuk 2D; (3) Window display dengan interior bergaya tradisional Jawa menggunakan komposisi warna monochrome dan objek pendukung (props) berbentuk 2D; (4) Window display interior bergaya tradisional Jawa menggunakan komposisi warna Yogyakarta dan objek pendukung (props) berbentuk 3D; dan (5) Window display dengan interior bergaya tradisional Jawa menggunakan komposisi warna monochrome dan objek pendukung (props) berbentuk 3D. Simulasi digital diberikan secara online kepada subjek penelitian. Saat mengamati simulasi digital, subjek penelitian mengisi kuesioner yang telah disediakan. Variabel-variabel dependent yang akan dipilih oleh subjek penelitian diukur melalui kuesioner menggunakan skala likert $(1-5)$.

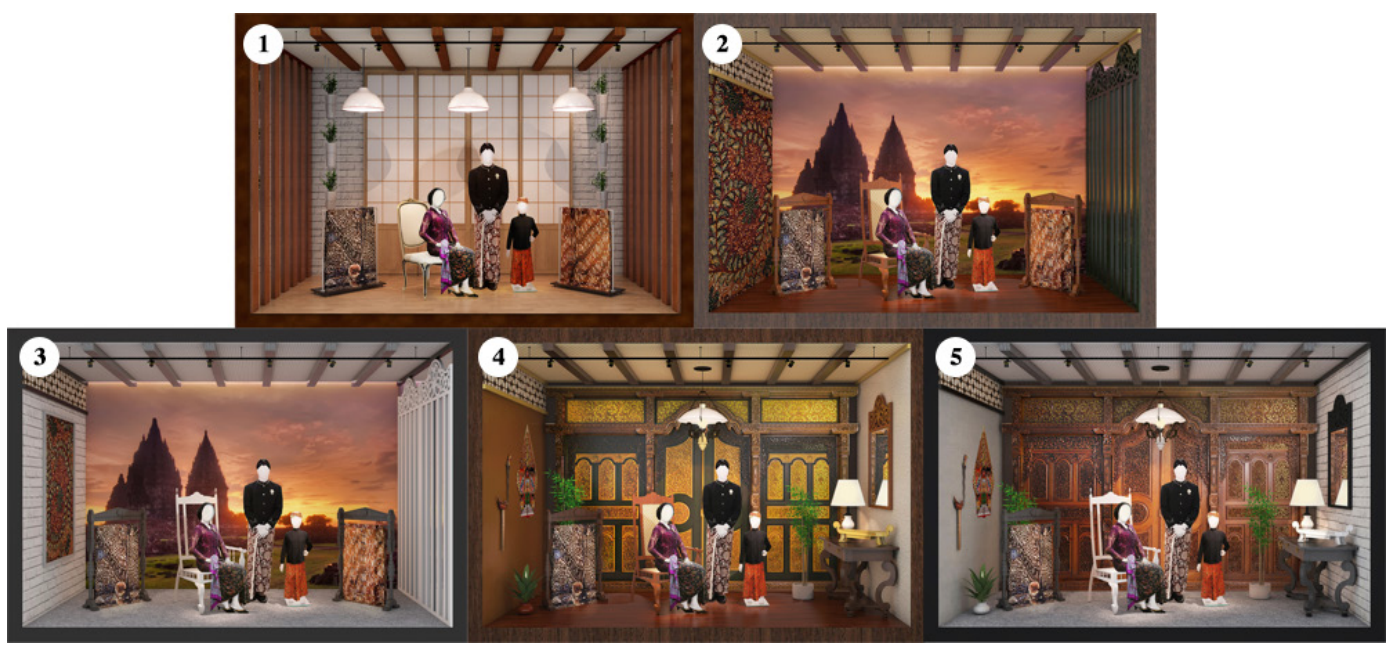

Gambar 5. Stimulus Eksperimen: (1) gaya modern (Modern); (2) gaya tradisional Jawa, komposisi warna Yogyakarta dan objek pendukung (props) 2D (A1); (3) gaya tradisional Jawa, komposisi warna monochrome dan objek pendukung (props) 2D (A2); (4) gaya tradisional Jawa, komposisi warna Yogyakarta dan objek pendukung (props) 3D (B1); dan (5) gaya tradisional Jawa, komposisi warna monochrome dan objek pendukung (props) 3D (B2).

\section{HASIL DAN PEMBAHASAN}

\section{Uji Validitas}

Validitas adalah tingkat keandalan dan kesahihan alat ukur yang digunakan. Intrumen dikatakan valid berarti menunjukkan alat ukur yang dipergunakan untuk mendapatkan data itu valid atau dapat digunakan untuk mengukur apa yang seharusnya di ukur (Sugiyono, 2004). Dengan demikian, instrumen yang valid merupakan instrumen yang benar-benar tepat untuk mengukur apa yang hendak di ukur. Atau bisa dikatakan Validitas (Validity) yaitu sejauh mana suatu alat ukur tepat dalam mengukur suatu data, dengan kata lain apakah alat ukur yang dipakai memang mengukur sesuatu yang ingin diukur. Berikut ini merupakan hasil uji validitas pada variabel Customer Perceived Value (CPV): 
Tabel 2. Hasil Uji Validitas

\begin{tabular}{|c|c|c|}
\hline \multicolumn{3}{|c|}{ KMO and Bartlett's Test } \\
\hline \multicolumn{2}{|c|}{ Kaiser-Meyer-Olkin Measure of Sampling Adequacy. } & .841 \\
\hline \multirow[t]{3}{*}{ Bartlett's Test of Sphericity } & Approx. Chi-Square & 1500.251 \\
\hline & df & 6 \\
\hline & Sig. & .000 \\
\hline
\end{tabular}

Berdasarkan Tabel 2 dapat dilihat bahwa Kaiser-Meyer-Olkin Measure of Sampling Adequacy atau KMO MSA dari variabel CPV lebih besar dari 0.5, yaitu 0.841. Hal ini menunjukkan bahwa seluruh item secara bersama-sama valid untuk diuji terhadap konstruk CPV atau memiliki interdependensi terhadap konstruk CPV.

\section{Uji Reliabilitas}

Uji reliabilitas digunakan untuk mengetahui konsistensi alat ukur, apakah alat pengukur yang digunakan dapat diandalkan dan tetap konsisten jika pengukuran tersebut diulang. Reliabilitas berarti dapat dipercaya. Artinya, instrumen dapat memberikan hasil yang tepat. Uji reliabilitas berguna untuk menetapkan apakah instrumen yang dalam hal ini kuesioner dapat digunakan lebih dari satu kali, paling tidak oleh responden yang sama akan menghasilkan data yang konsisten. Dengan kata lain, reliabilitas instrumen mencirikan tingkat konsistensi. (Harrison, dalam Zulganef, 2006). Nilai koefisien reliabilitas atau Cronbach's Alpha yang baik adalah diatas 0,6. Berikut ini merupakan hasil uji reliabilitas pada variabel Customer Perceived Value (CPV):

\begin{tabular}{|c|c|c|}
\hline \multicolumn{3}{|c|}{ Case Processing Summary } \\
\hline Cases & $\mathrm{N}$ & $\%$ \\
\hline Valid & 425 & 100.0 \\
\hline Excluded & 0 & .0 \\
\hline Total & 425 & 100.0 \\
\hline \multicolumn{3}{|c|}{ Reliability Statistics } \\
\hline Cronbach's Alpha & $\mathrm{N}$ of & \\
\hline .936 & & 4 \\
\hline
\end{tabular}

Berdasarkan Tabel 3 dapat dilihat bahwa Cronbach's Alpha dari variabel CPV lebih besar dari 0.6, yaitu 0.936. Hal ini menunjukkan bahwa seluruh item secara bersama-sama memiliki hubungan positif terhadap konstruk CPV atau dengan kata lain seluruh variabel reliable untuk diuji.

\section{UJI-T UNTUK SAMPEL BEBAS (INDEPENDENT SAMPLES T-TEST)}

Independent samples t-test digunakan apabila terdapat dua kondisi eksperimental yang berbeda dan peserta yang berbeda dalam setiap kondisi (Field, 2009). Uji-t ini bertujuan untuk mengetahui perbedaan rata-rata dari dua kelompok atau sampel yang berbeda. Pada penelitian ini terdapat dua kelompok gaya (style) interior yang akan dibandingkan, yaitu interior bergaya modern dan interior bergaya tradisional Jawa. Perbedaan rata-rata dari variabel dependent customer perceived value pada kelompok desain modern dan kelompok desain tradisional Jawa dapat diketahui melalui uji-t untuk sampel bebas (independent samples t-test) dengan bantuan SPSS 23. Hasil uji-t untuk sampel bebas (independent samples t-test) penelitian ini adalah sebagai berikut: 
Tabel 4. Hasil Uji Independent Samples t-Test

\begin{tabular}{|c|c|c|c|c|c|c|c|c|c|c|}
\hline \multicolumn{11}{|c|}{ Independent Samples Test } \\
\hline & & \multicolumn{2}{|c|}{$\begin{array}{l}\text { Levene's Test for } \\
\text { Equality of } \\
\text { Variances }\end{array}$} & \multicolumn{4}{|c|}{ t-test for Equality of Means } & \multicolumn{3}{|c|}{ t-test for Equality of Means } \\
\hline & & \multirow{2}{*}{$\mathrm{F}$} & \multirow{2}{*}{ Sig. } & \multirow{2}{*}{$\mathrm{t}$} & \multirow{2}{*}{ df } & \multirow{2}{*}{$\begin{array}{l}\text { Sig. } \\
(2- \\
\text { tailed })\end{array}$} & \multirow{2}{*}{$\begin{array}{c}\text { Mean } \\
\text { Difference }\end{array}$} & \multirow{2}{*}{$\begin{array}{l}\text { Std. Error } \\
\text { Difference }\end{array}$} & \multicolumn{2}{|c|}{$\begin{array}{l}95 \% \text { Confidence Interval } \\
\text { of the Difference }\end{array}$} \\
\hline & & & & & & & & & Lower & Upper \\
\hline \multirow[t]{2}{*}{$\mathrm{CPV}$} & $\begin{array}{l}\text { Equal } \\
\text { variances } \\
\text { assumed }\end{array}$ & 6.637 & .010 & -13.756 & 423 & .000 & -24.14338 & 1.75507 & -27.59312 & -20.69364 \\
\hline & $\begin{array}{l}\text { Equal } \\
\text { variances not } \\
\text { assumed }\end{array}$ & & & -12.696 & 116.3 & .000 & -24.14338 & 1.90169 & -27.90982 & -20.37694 \\
\hline
\end{tabular}

Berdasarkan Tabel 4 dapat dilihat bahwa nilai signifikansi pada kolom t-test for Equality of Means dari variabel CPV pada seluruh simulasi digital lebih kecil dari 0.05 , yaitu 0.000. Oleh karena itu, dapat dikatakan bahwa CPV dari produk batik keraton Yogyakarta pada window display dengan desain modern dan CPV dari produk batik keraton Yogyakarta pada window display dengan desain tradisional Jawa pada dasarnya berbeda.

Tabel 5. Group Statistics untuk Variabel CPV dengan Jenis Desain

\begin{tabular}{|llllrr|}
\hline \multicolumn{5}{|c|}{ Group Statistics } \\
\hline \multicolumn{1}{|c}{ Jenis Desain } & N & Mean & Std. Deviation & Std. Error Mean \\
\hline CPV & Modern & 84 & 46.8214 & 15.98505 & 1.74411 \\
& 2D Warna Jawa (A1) & 86 & 73.7907 & 8.92863 & .96280 \\
2D Warna Monokrom (A2) & 84 & 60.4405 & 11.22535 & 1.22479 \\
3D Warna Jawa (B1) & 87 & 80.5057 & 9.74426 & 1.04469 \\
3D Warna Monokrom (B2) & 84 & 68.7143 & 16.59988 & 1.81120 \\
\hline
\end{tabular}

Berdasarkan Tabel 5 dapat diketahui bahwa nilai rata-rata (mean) pada setiap jenis desain tradisional (A1, A2, B1, dan B2) lebih tinggi dibandingkan dengan nilai nilai ratarata (mean) pada jenis desain modern. Dengan demikian dapat dikatakan bahwa customer perceived value dari produk batik keraton Yogyakarta pada window display dengan desain tradisional Jawa lebih tinggi dibandingkan dengan dan customer perceived value dari produk batik keraton Yogyakarta pada window display dengan desain modern.

\section{UJI TWO-WAY ANOVA}

Two-Way ANOVAdisebut juga dengan ANOVA 2 Arah atau Analisis Varian 2 Faktor. ANOVA dua arah membandingkan perbedaan rata-rata antara kelompok yang telah dibagi pada dua variabel independen (disebut faktor). (Santoso, 2010). Faktor lain yang mungkin menjadi sumber keragaman respon juga harus diperhatikan. Faktor lain ini bisa perlakuan lain atau faktor yang sudah terkondisi. Tujuan dan pengujian ANOVA dua arah ini adalah untuk mengetahui apakah ada pengaruh dari berbagai kriteria yang diuji terhadap hasil yang diinginkan. Pada penelitian ini akan diketahui sejauh mana pengaruh variabel independent komposisi warna dan variabel independent objek pendukung/props terhadap variabel dependent customer perceived value. Melalui uji hipotesis ANOVA akan diperoleh secara detail perbandingan pengaruh stimulus penelitian ((1) Window display dengan interior bergaya tradisional Jawa menggunakan komposisi warna Yogyakarta dan objek pendukung (props) berbentuk 2D; (2) Window display dengan interior bergaya tradisional Jawa menggunakan komposisi warna monochrome dan objek pendukung (props) berbentuk 2D; (3) Window display interior bergaya tradisional Jawa menggunakan komposisi warna Yogyakarta dan objek pendukung (props) berbentuk 3D; dan (4) Window display dengan 
interior bergaya tradisional Jawa menggunakan komposisi warna monochrome dan objek pendukung (props) berbentuk 3D terhadap penilaian subjek penelitian pada customer perceived value.

Tabel 6. Tests of Between-Subjects Effects pada Uji Two-Way ANOVA

\begin{tabular}{|c|c|c|c|c|c|c|}
\hline \multicolumn{7}{|c|}{ Tests of Between-Subjects Effects } \\
\hline \multicolumn{7}{|c|}{ Dependent Variable: CPV } \\
\hline Source & $\begin{array}{l}\text { Type III Sum } \\
\text { of Squares }\end{array}$ & $\mathrm{df}$ & Mean Square & $\mathrm{F}$ & Sig. & $\begin{array}{l}\text { Partial Eta } \\
\text { Squared }\end{array}$ \\
\hline Corrected Model & $18335.753 a$ & 3 & 6111.918 & 42.669 & .000 & .275 \\
\hline Intercept & 1711947.672 & 1 & 1711947.672 & 11951.617 & .000 & .973 \\
\hline Objek & 4787.084 & 1 & 4787.084 & 33.420 & .000 & .090 \\
\hline Warna & 13468.603 & 1 & 13468.603 & 94.028 & .000 & .218 \\
\hline Objek * Warna & 51.772 & 1 & 51.772 & .361 & .548 & .001 \\
\hline Error & 48271.825 & 337 & 143.240 & & & \\
\hline Total & 1783885.000 & 341 & & & & \\
\hline Corrected Total & 66607.578 & 340 & & & & \\
\hline
\end{tabular}

a. R Squared $=.275$ (Adjusted R Squared $=.269$ )

Berdasarkan Tabel 6 dapat diketahui bahwa hubungan antara jenis objek dan jenis warna yang digunakan pada simulasi digital window display dengan customer perceived value memiliki tingkat signifikansi (Sig.) $0.000<0.05$. Hal ini menunjukkan bahwa terdapat perbedaan customer perceived value yang diakibatkan oleh perbedaan jenis objek yang digunakan, sedangkan hubungan antara jenis objek dan warna yang digunakan pada simulasi digital window display dengan customer perceived memiliki tingkat signifikansi (Sig.) $0.548>0.05$. Hal ini menunjukkan bahwa perbedaan jenis objek pada simulasi digital window display tidak tergantung pada perbedaan jenis warna pada simulasi digital window display atau perbedaan jenis warna pada simulasi digital window display tidak tergantung pada perbedaan jenis objek pada simulasi digital window display terhadap customer perceived.

Tabel 7. Post Hoc Test pada Uji Two-Way ANOVA

\begin{tabular}{|c|c|c|c|c|c|c|}
\hline \multicolumn{7}{|c|}{ Multiple Comparisons } \\
\hline \multirow{2}{*}{\multicolumn{7}{|c|}{$\begin{array}{l}\text { Dependent Variable: CPV } \\
\text { Scheffe }\end{array}$}} \\
\hline & & & & & & \\
\hline \multirow{2}{*}{$\begin{array}{l}\text { (I) Jenis } \\
\text { Desain }\end{array}$} & \multirow{2}{*}{$\begin{array}{l}(\mathrm{J}) \text { Jenis } \\
\text { Desain }\end{array}$} & \multirow{2}{*}{$\begin{array}{c}\text { Mean } \\
\text { Difference (I-J) }\end{array}$} & \multirow[t]{2}{*}{ Std. Error } & \multirow[t]{2}{*}{ Sig. } & \multicolumn{2}{|c|}{ 95\% Confidence Interval } \\
\hline & & & & & Lower Bound & Upper Bound \\
\hline \multirow[t]{3}{*}{ 2D Jawa } & 2D Monokrom & $3.33756^{*}$ & .45899 & .000 & 2.0479 & 4.6272 \\
\hline & 3D Jawa & $-1.67876^{*}$ & .45497 & .004 & -2.9571 & -.4004 \\
\hline & 3D Monokrom & 1.26910 & .45899 & .056 & -.0205 & 2.5587 \\
\hline \multirow[t]{3}{*}{ 2D Monokrom } & 2D Jawa & $-3.33756^{*}$ & .45899 & .000 & -4.6272 & -2.0479 \\
\hline & 3D Jawa & $-5.01632 *$ & .45769 & .000 & -6.3023 & -3.7304 \\
\hline & 3D Monokrom & $-2.06845^{*}$ & .46169 & .000 & -3.3656 & -.7713 \\
\hline \multirow[t]{3}{*}{ 3D Jawa } & 2D Jawa & $1.67876^{*}$ & .45497 & .004 & .4004 & 2.9571 \\
\hline & 3D Jawa & $5.01632 *$ & .45769 & .000 & 3.7304 & 6.3023 \\
\hline & 3D Monokrom & $2.94787 *$ & .45769 & .000 & 1.6619 & 4.2338 \\
\hline \multirow[t]{3}{*}{ 3D Monokrom } & 2D Jawa & -1.26910 & .45899 & .056 & -2.5587 & .0205 \\
\hline & 3D Jawa & $2.06845^{*}$ & .46169 & .000 & .7713 & 3.3656 \\
\hline & 3D Monokrom & $-2.94787^{*}$ & .45769 & .000 & -4.2338 & -1.6619 \\
\hline
\end{tabular}

*. The mean difference is significant at the 0.05 level. 
Hasil post hoc test dengan mudah bisa dilihat pada output dengan ada atau tidak adanya tanda "*” pada kolom "Mean Difference". Jika tanda * ada pada angka mean difference maka perbedaan tersebut nyata atau signifikan. Jika tidak ada tanda *, maka perbedaan tidak signifikan. Berdasarkan Tabel 7 dapat diketahui bahwa hampir seluruh pada penggunaan variasi objek dan warna pada simulasi digital window display menghasilkan customer perceived value yang berbeda secara signifikan, kecuali pada jenis desain dengan objek 2D warna Jawa dan desain dengan objek 3D warna monokrom tidak terdapat perbedaan customer perceived value yang signifikan. Perbedaan customer perceived value dapat dilihat lebih jelas pada Tabel 8 berikut:

Tabel 8. Homogeneous Subsets pada Uji Two-Way ANOVA

\begin{tabular}{|c|c|c|c|c|}
\hline \multicolumn{5}{|c|}{ CPV } \\
\hline \multicolumn{5}{|l|}{ Scheffe $a, b$} \\
\hline \multirow{2}{*}{ Jenis Desain } & \multirow{2}{*}{$\mathbf{N}$} & \multicolumn{3}{|c|}{ Subset for alpha $=0.05$} \\
\hline & & 1 & 2 & 3 \\
\hline 2D Monokrom & 84 & 15.1101 & & \\
\hline 3D Monokrom & 84 & & 17.1786 & \\
\hline 2D Jawa & 86 & & 18.4477 & \\
\hline 3D Jawa & 87 & & & 20.1264 \\
\hline Sig. & & 1.000 & .055 & 1.000 \\
\hline \multicolumn{5}{|c|}{ Means for groups in homogeneous subsets are displayed. } \\
\hline \multicolumn{5}{|c|}{ a. Uses Harmonic Mean Sample Size $=85.230$. } \\
\hline \multicolumn{5}{|c|}{$\begin{array}{l}\text { b. The group sizes are unequal. The harmonic mean of the group sizes is used. Type I } \\
\text { error levels are not guaranteed. }\end{array}$} \\
\hline
\end{tabular}

Berdasarkan Tabel 8 dapat diketahui bahwa jenis desain window display yang paling baik untuk meningkatkan customer perceived value adalah jenis desain dengan objek pendukung (props) 3D dan skema warna Jawa/Yogyakarta. Hal ini dapat dilihat dari nilai rata-rata (mean) tertinggi pada jenis desain 3D Jawa, sedangkan jenis desain window display yang kurang baik untuk meningkatkan customer perceived value adalah jenis desain dengan objek pendukung (props) 2D dan skema warna monokrom. Tidak terdapat perbedaan yang signifikan pada penggunaan jenis desain 3D monokrom dan jenis desain 2D Jawa akibat dari perbedaan rata-rata (mean) yang tidak begitu jauh, yaitu 17.1786 pada jenis desain 3D monokrom dan 18.4477 pada jenis desain 2D Jawa. Hasil pada Tabel 8 menyimpulkan bahwa faktor warna lebih berpengaruh dibandingkan dengan faktor objek pendukung (props) pada simulasi digital window display dalam peningkatan customer perceived value.

\section{PEMBAHASAN}

Pembentukan customer perceived value pada penelitian ini didasarkan pada persepsi visual pengunjung melalui teori mengenai environmental behavior, sebuah sistem yang menjelaskan hubungan antara stimuli, organisme dan respon, kemudian dikenal dengan model $\mathrm{S}-\mathrm{O}-\mathrm{R}$ (Yoon, 2012). Interaksi antara stimuli yang berasal dari lingkungan sekitar ( $\mathrm{S}$ ) dengan respon perilaku manusia (R) dimediasi oleh tanggapan emosional individu (O). Stimuli (S) yang berasal dari simulasi digital window display merupakan faktor eksternal yang berupa elemen fisik yang dapat diterima oleh sistem sensorik manusia, seperti warna dan objek pendukung (props). Organisme (O) pada penelitian merupakan tanggapan emosional responden terhadap quality value, emotional value, price value, dan social value saat responden merasakan stimuli. Respon internal $(\mathrm{R})$ responden 
pada penelitian ini dapat dikategorikan sebagai respon afektif terhadap customer perceived value dari produk batik keraton Yogyakarta.

\section{PENGARUH DESAIN WINDOW DISPLAY TERHADAP CUSTOMER PERCEIVED VALUE DARI PRODUK BATIK KERATON YOGYAKARTA}

Dalam merancang sebuah window display, hal pertama yang perlu dilakukan adalah menentukan sebuah tema dan suasana apa yang ingin diterapkan, kemudian menemukan ide dari tema tersebut agar membuat tema secara visual menjadi spesial (Banchet dalam Morgan, 2008). Tema dan skema pada window display mengacu pada elemen kreatif yang akan digunakan untuk mendukung produk yang dipajang. Kedua hal tersebut, tema dan skema, saling berhubungan untuk membuat window display menjadi sebuah kesatuan. Perancang visual merchandise menggunakan tema dan skema untuk menciptakan drama, memberikan cerita, dan menginspirasi pada pengunjung. Window display pada penelitian ini dirancang dengan tema dan skema interior bergaya Jawa dan interior bergaya modern. Tema dan skema interior bergaya Jawa dipilih untuk menciptakan suasana yang mampu menonjolkan produk batik keraton Yogyakarta, sedangkan tema dan skema interior bergaya modern dipilih sebagai pembanding atau sebagai desain standard dari window display pada toko-toko batik ternama di Indonesia. Penggunaan tema dan skema interior bergaya Jawa pada window display dinilai lebih menciptakan suasana yang menonjolkan produk batik keraton Yogyakarta sehingga mampu meningkatkan customer perceived value dari produk batik keraton Yogyakarta di toko fashion dibandingkan dengan penggunaan tema dan skema interior bergaya modern karena tema dan skema interior bergaya Jawa mendukung produk yang dipajang dengan memberikan elemen kreatif suasana Jawa.

\section{PENGARUH KOMPOSISI WARNA PADA WINDOW DISPLAY TERHADAP CUSTOMER PERCEIVED VALUE DARI PRODUK BATIK KERATON YOGYAKARTA}

Penerapan warna dalam ruang dapat menimbulkan berbagai macam kesan psikologis (Hasle, dalam Widasati 2011). Contohnya penggunaan warna yang terang (bright) dapat membuat sebuah ruang terlihat lebih luas daripada ukuran ruang yang sesungguhnya. Hal tersebut dikarenakan warna-warna terang lebih menstimulasi retina mata dibandingkan dengan warna-warna gelap. Namun selain itu, kehadiran warna dalam ruang dipengaruhi pula oleh berbagai faktor diantaranya kondisi lingkungan sekitar, ukuran penempatan warna, penempatan warna pada elemen interior dan sudut pandang. Penempatan warna pada elemen interior, yaitu langit-langit, dinding dan lantai merupakan salah satu faktor yang dapat memberikan kesan ruang dan menimbulkan efek psikologis yang berbedabeda (Mahnke, 1996). Komposisi warna yang digunakan pada penelitian ini dibatasi pada komposisi warna Yogyakarta dan warna monochrome yang diterapkan pada simulasi digital window display. Warna Yogyakarta dipilih karena menurut Purbasari (2014) warna-warna ini banyak ditemui di artefakartefak (batik, wayang, makanan) dan merupakan warna keraton atau warna raja yang terdapat pada arsitektur dan interior Keraton Yogyakarta. Warna coklat memiliki arti rasa kerendahan diri, kesederhanaan dan mem"bumi"; warna hijau memiliki arti harapan, kemakmuran, kesejahteraan, dan kehormatan; dan warna kuning emas bermakna kewibawaan dan kejayaan. Sedangkan skema warna monochrome dipilih karena menurut Morgan (2008), komposisi dengan satu warna atau monochrome merupakan komposisi warna yang paling efektif digunakan pada storefront dan window display.

Kehadiran warna dalam ruang dipengaruhi pula oleh berbagai faktor diantaranya 
kondisi lingkungan sekitar, ukuran penempatan warna, penempatan warna pada elemen interior dan sudut pandang. Penempatan warna pada elemen interior, yaitu langit-langit, dinding dan lantai merupakan salah satu faktor yang dapat memberikan kesan ruang dan menimbulkan efek psikologis yang berbeda-beda (Mahnke, 1996). Hasil penelitian ini mendukung teori tersebut bahwa warna memberikan kesan ruang dan menimbulkan efek psikologis yang berbeda-beda, yaitu penggunaan skema warna Jawa/Yogyakarta lebih meningkatkan customer perceived value dari produk batik yang dipajang dibandingkan dengan penggunaan skema warna monokrom pada simulasi digital window display. Hal tersebut dapat dilihat dari nilai pada simulasi digital yang menggunakan skema warna Jawa/Yogyakarta (simulasi A1 dan B1) yang lebih tinggi dibandingkan dengan nilai pada simulasi digital yang menggunakan skema warna Jawa/Yogyakarta (simulasi A2 dan B2). Hasil tersebut mendukung temuan penelitian yang dilakukan pada tahun 2014 oleh Hanna Kiehelä, yaitu elemen warna pada retail design berpengaruh pada pembentukan perceived value pada produk yang dijual. Penggunaan skema warna Jawa/Yogyakarta lebih efektif dalam meningkatkan customer perceived value dari produk batik keraton Yogyakarta karena warna-warna yang digunakan memiliki arti tersendiri yang menggambarkan kehidupan orang Jawa, seperti warna kuning yang melambangkan kekayaan dan kejayaan. Dalam masyarakat jawa warna ini merupakan simbolisasi warna emas yang pasti warnanya kuning. Semakin banyak emas maka kerajaan itu semakin makmur. Warna hijau yang melambangkan alam, harapan, hidup dan harapan yang selalu mendampingi kita. Maksudnya adalah kita selalu hidup berdampingan dengan alam dan selalu mendapatkan semuanya dari alam. Warna coklat yang melambangkan persahabatan dan kekeluargaan dalam Jawa, kejadian yang khusus, pemikiran yang materialis, reliabilitas, kedamaian, produktivitas, praktis, kerja keras.

\section{PENGARUH OBJEK PENDUKUNG (PROPS) PADA WINDOW DISPLAY TERHADAP CUSTOMER PERCEIVED VALUE DARI PRODUK BATIK KERATON YOGYAKARTA}

Objek pendukung (props) merupakan bagian yang tidak terpisahkan dari suatu window display. Objek pendukung (props) adalah sesuatu yang digunakan untuk meningkatkan tampilan produk dan menceritakan sebuah cerita atau melengkapkan tema dalam window display (Morgan, 2008). Objek pendukung (props) adalah objek-objek atau barang-barang yang mampu melengkapi atau menonjolkan barang sehingga window display terlihat menarik. Dalam memilih objek pendukung (props), perlu diingat bahwa barang dagangan harus menjadi elemen dominan dalam komposisi keseluruhan di window display, atau dengan kata lain objek pendukung (props) tidak boleh mengalihkan perhatian pengunjung dari fokus utama (barang dagangan) melainkan harus menjadi pendukung yang memaksa pengunjung untuk melihat fokus utama (barang dagangan) dari window display. Sebagai contoh, props dapat berupa lampu lentera, gambar kebudayaan tradisional Jepang dan kursi (layout ini berusaha menceritakan tentang keadaan suasana jalanan kota Jepang yang vintage), produk sepatu dimasukkan ke dalam lemari sepatu mengesankan seperti milik sendiri. Hal tersebut adalah suatu upaya agar pengunjung dapat melihat produk sepatu tersebut sebagai produk tradisional Jepang dengan merasakan suasana rumah Jepang. Dalam penelitian ini, objek pendukung (props) dibagi menjadi 2 (dua) jenis, yaitu objek pendukung (props) berbentuk dua dimensi (2D) dan objek pendukung (props) berbentuk tiga dimensi (3D) yang mampu mendukung penciptaan suasana interior tradisional Jawa.

Penggunaan objek pendukung (props) berbentuk 3D menimbulkan estetika simbolik yang membuat responden menilai suatu obyek berdasarkan makna konotatif dari obyek 
tersebut setelah dialami oleh pengamat, apakah suatu benda memiliki arti sehingga menimbulkan keindahan (berdasarkan teori Nassar, 1988). Hasil tersebut mendukung teori Nassar (1988), yaitu objek pendukung berupa tekstur atau tiga dimensional merupakan salah satu sumber daya visual penting karena dapat meningkatkan kualitas lingkungan dan memberikan efek visual yang menyenangkan. Dengan kualitas lingkungan dan efek visual yang menyenangkan bagi pengunjung tentu akan meningkatkan customer perceived value akan suatu produk, dalam penelitian ini adalah produk batik keraton Yogyakarta.

\section{KESIMPULAN}

Hasil eksperimen dan hasil analisis yang telah dipaparkan sebelumnya dapat disimpulkan melalui Skema dalam Gambar 6, yaitu berdasarkan hasil eksperimen diketahui bahwa Window display pada toko fashion yang menggunakan elemen desain tradisional Jawa dapat meningkatkan customer perceived value dibandingkan dengan window display yang menggunakan elemen desain modern. Total customer perceived value dari produk batik yang dipajang pada simulasi digital dengan skema warna Jawa/Yogyakarta dan menggunakan objek pendukung (props) dalam bentuk 3D paling tinggi dibandingkan dengan simulasi lainnya. Hal tersebut dapat dikarenakan penggunaan skema warna Jawa/Yogyakarta dan objek pendukung (props) berbentuk 3D mampu memaksimalkan tampilan window display sehingga menciptakan persepsi visual bagi pengunjung terhadap performance/quality value, emotional value, price value, dan social value dari produk batik yang dipajang sehingga customer perceived value dari produk batik yang dipajang pun meningkat.

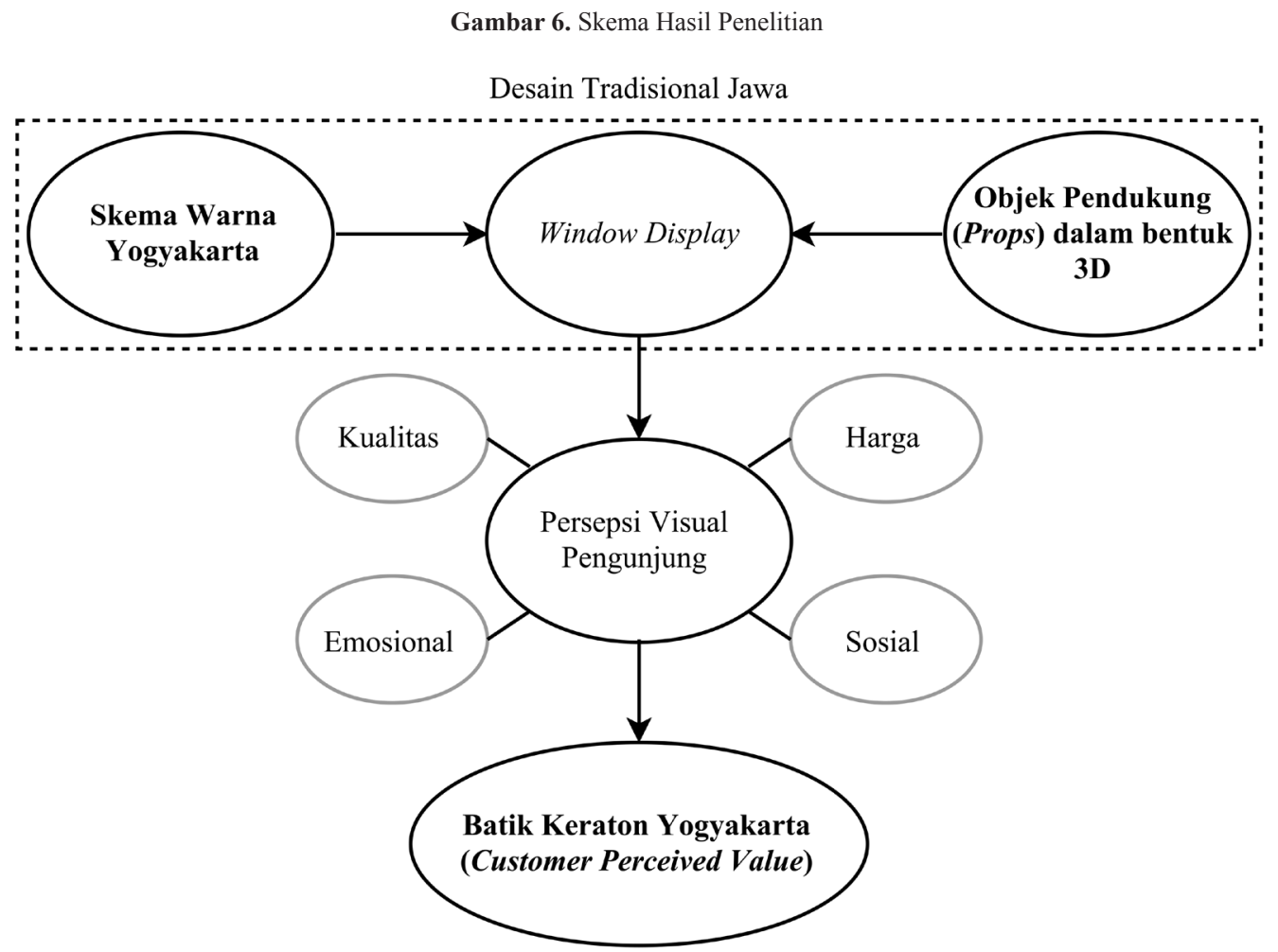

Melalui hasil penelitian dapat disimpulkan bahwa seluruh hipotesis yang diajukan dalam penelitian ini diterima. 
Tabel 9. Hasil Pengujian Hipotesis

\begin{tabular}{|l|l|l|}
\hline H1 & $\begin{array}{l}\text { Desain window display di toko fashion berpengaruh terhadap customer perceived } \\
\text { value dari produk batik keraton Yogyakarta. }\end{array}$ & Hipotesis Diterima \\
\hline H2 & $\begin{array}{l}\text { Penggunaan elemen desain tradisional Jawa pada window display di toko fashion } \\
\text { dapat meningkatkan customer perceived value dari produk batik keraton Yogyakarta. }\end{array}$ & Hipotesis Diterima \\
\hline $\mathbf{H 3}$ & $\begin{array}{l}\text { Komposisi warna Jawa/Yogyakarta dan objek pendukung (props) dalam bentuk tiga } \\
\text { dimensi (3D) pada window display di toko fashion dapat meningkatkan customer } \\
\text { perceived value dari produk batik keraton Yogyakarta. }\end{array}$ & Hipotesis Diterima \\
\hline
\end{tabular}

SARAN

Hasil penelitian ini akan lebih efektif bila dilakukan eksperimen secara nyata, tanpa manipulasi desain secara digital dan juga tidak dilakukan secara online agar peneliti dapat lebih mengawasi jalannya eksperimen dan tidak terjadi bias pada penyampaian informasi terkait eksperimen. Eksperimen secara nyata perlu dilakukan agar subjek penelitian dapat benar-benar merasakan secara langsung kondisi ruang dari stimulus melalui seluruh panca indera. Manipulasi desain secara digital, terutama dilakukan secara online tentunya membuat subjek penelitian menjalani eksperimen dengan kondisi yang tidak sama satu sama lain, hal tersebut membuat kondisi seluruh subjek penelitian yang tidak dapat dikontrol oleh peneliti sehingga dapat berpengaruh pada hasil penelitian. Selain itu, dapat menggunakan jumlah sampel yang lebih banyak dan sampel dapat berasal dari kelompok tertentu terkait topik penelitian, karena pada penelitian ini jumlah sampel yang digunakan tidak begitu banyak dan secara acak hanya berasal dari kelompok usia 20-65 tahun yang tidak dipertimbangkan faktor latar belakang kebudayaan atau suku bangsanya.

Penelitian ini berhubungan dengan disiplin-disiplin ilmu lain, seperti pemasaran, sosial, fashion, budaya, dan lain-lain sehingga diperlukan suatu kerjasama untuk memperoleh sejumlah pengetahuan serta informasi lainnya demi menunjang kegiatan penelitian. Penelitian ini membahas mengenai suatu kelompok masyarakat (Jawa) dan warisan budaya dari daerah tersebut, yang berarti masyarakat dapat menjadi sumber informasi penting yang berguna bagi kegiatan penelitian, sehingga diharapkan adanya suatu relasi yang baik dengan masyarakat guna mendukung penelitian.

\section{DAFTAR PUSTAKA}

Field, A. (2009): Discovering Statistics Using SPSS. London: SAGE

Kiehelä, H. (2014): Dimensionality of the Consumer Perceived Value of Product Colour. Helsinki: Edita Prima Ltd

Mahnke, F.H. (1996): Color, Environment, and Human Response. New York: John Wiley \& Sons, Inc

Morgan, T. (2008): Visual Merchandising - Window and In-Store Displays for Retail. London: Laurence King Publishing

Mun, D. (1981): Shops: A Manual of Planning and Design. London: The Architectural Press

Nassar, M.M., (1988): Two Properties of Mixtures of Exponential Distributions. IEEE Trans. Raliab, Vol. 37 (4): pp 383-385

Purbasari, M, dkk. (2014): Analisis Asosiasi Kultural atas Warna. Humaniora, Vol. 5(1): pp 172-184

Santoso, S. (2010): Statistik Parametrik. Jakarta: PT Elex Media Komputindo 
Somoon, K, \& Chumporn M. (2016) The Roles of Aesthetic and Cultural Perception Affected by Window Display of Thai crafts products to Increase Purchasing Intention. Procedia - Social and Behavioral Sciences, Vol. 234 : pp 55-63

Sugiyono, (2004): Metode penelitian Kualitatif, dan R\&D. Jakarta: Alfabet

Tordiglione, S. (2015): First Impressions: Shopfront Design Ideas. Hong Kong: Design Media Publishing Limited

Widasati, A. (2011): Pengaruh Cahaya dan Warna pada Window Display terhadap Perilaku Pengunjung. Tesis: Institut Teknologi Bandung

Yildrim, K., Baskaya, A.A., \& Hidayetoglu, L.M. (2007): The Effects of The Store Window Type on Consumer's Perception and Shopping Attitudes Through the Use of Digital Pictures. G.U. Journal of Science, Vol, 20 (2): pp 33-40

Yoon, Eunju. (2012). Effects of Website Environmental Cues on Consumers'Response and Outcome Behaviors. Tesis: University of Nebraska Zulganef. (2006): Pemodelan Persamaan Struktural \& Aplikasinya Menggunakan Amos 5. Bandung: Pustaka 